\title{
THE USE OF A SPECIAL SOFTWARE FOR INDUCTION MOTOR DIAGNOSTICS IN THE DIAMOND INDUSTRY
}

\author{
Vladislav A. Shevchuk ${ }^{1}$, Oleg P. Muravlev ${ }^{1}, \quad$ Olga O. Stolyarova ${ }^{1, *}$, and \\ Vladimir P. Shevchuk ${ }^{2}$ \\ ${ }^{1}$ Tomsk Polytechnic University, 634050, Tomsk, Russia \\ ${ }^{2}$ DC “ALROSA”, Yakutia, Mirny
}

\begin{abstract}
The field of induction motor application in the diamond industry has considerably increased due to the transition to the underground mining method. This article is devoted to the research the induction motor diagnostic technique in the diamond industry using special software. The practice shows that unreliability of induction motors causes some serious economic losses related to the expenses on premature maintenance and idle time. This article is devoted to the research of diagnostic technique of induction motors in the diamond industry using a special software. The article presents some data obtained in the course of the research conducted at an industrial site of the diamond company "ALROSA" in Mirny using the vibration-based diagnostics. Thus, based on the analysis of the findings some recommendations concerning the improvement of maintenance and servicing system have been given. The use of these recommendations allows assessing the operational reliability of induction motors in the diamond industry, minimizing the risk of sudden failures and reducing the maintenance and repair expenses.
\end{abstract}

\section{Introduction}

The field of induction motor application in the diamond industry has considerably increased due to the transition to underground mining methods. However, the induction motor unreliability leads to serious economic losses associated with the premature maintenance and idle time expenses. Therefore, there is an urgent problem to choose an adequate induction motor diagnostics technique without its stopping.

The main sources of induction motor failures are: bearing failures $-49 \%$; stator winding failures $-35 \%$; rotor winding failures $-10 \%$; other failures $-6 \%$ [1]

The relevance of this work is in the necessity to improve the maintenance and service system of a.c. machines through the selection of diagnostics technique under the existing conditions in the diamond industry.

The aim of this work is to research the induction motor diagnostic technique in the diamond industry using special software. The vibration-based diagnostic technique on a

\footnotetext{
*Corresponding author: muravlevaoo@tpu.ru
} 
root-mean-square value of vibration velocity is widely used in the diamond industry. This technique is based on the analysis of the induction motor vibration. Electric machines have some mechanical parts which cause vibrations. When tear and wear or destruction of mechanical part of the motor is observed, its frequency spectrum also undergoes some changes. Each fault (defect) causes extra vibrations of the induction motor with their distinctive features which can be measured, compared to the reference values and then the failures can be diagnosed [2]. Vibration is often measured by several sensors installed in different parts of the machine. The main idea is to analyze the root-mean-square value of vibration velocity (seldom - vibration acceleration) in different parts of the electric motor $[3,4,5]$.

The main advantages of this technique are as follows [3]:

- It does not require full stopping of the electric motor;

- Simplicity in implementation;

- $\quad$ Low cost, since very simple apparatuses are used to measure this vibration.

\section{Experimental procedure}

The diagnostics is carried out using the vibration signal analyzer "Quartz" with its further processing in software "Diamond-2".

The device "Quartz" is an autonomous microprocessor-based vibration analyzer. The device allows defining natural frequency and the waveforms of machine components, analyzing the vibration signal shape, measuring acceleration rate (characteristics) and aggregate rundown and performing diagnostics of the aggregate condition using spectral analysis. Data processing is performed in special software "Diamond-2". This special software allows considerably simplifying the problem of vibration-based diagnostics through automation of routine inspection processes as well as personal computer data input in the database and their analysis $[6,7,8]$.

At various plants of the DC "ALROSA" all operational information and technical reports on vibration-based diagnostics of electrical equipment has been thoroughly studied

Further we will consider the illustrations of this diagnostics. The diagnostics of the pump of the brand CPS 180-900 in the mine environment "International" is presented in Figures 1 and 2.

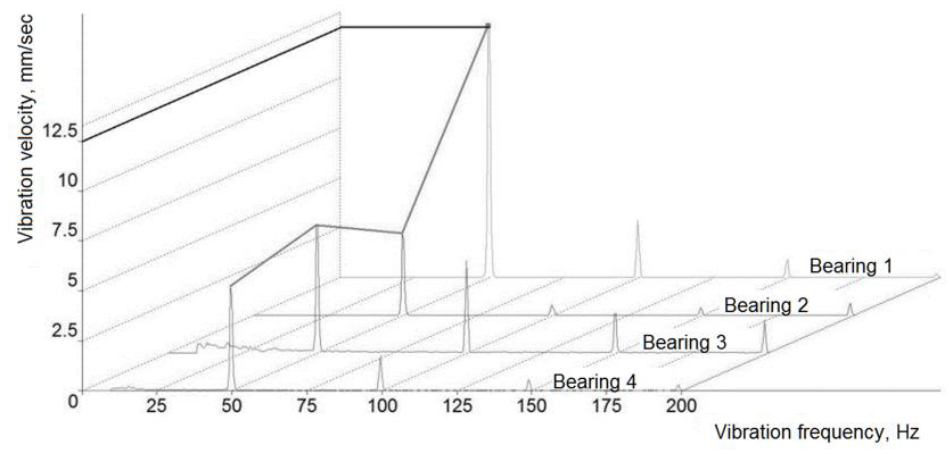

Fig. 1. Spectra cascade of vibration velocity, vertical direction.

Maximal level - on bearing 1 (electric motor). Rotational frequency $50 \mathrm{~Hz}$ and amplitude -12.5 $\mathrm{mm} / \mathrm{sec}$. are designated by cursor. 


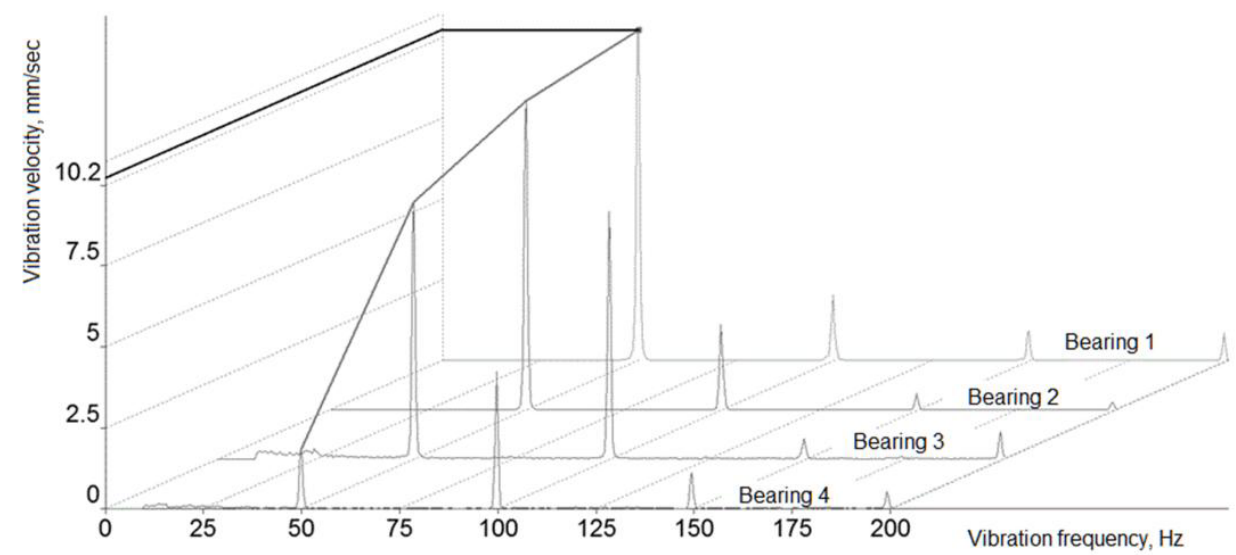

Fig. 2. Spectra cascade of vibration velocity, crosswise direction Maximal level (rate) - on bearing 1 (electric motor). Rotational frequency $50 \mathrm{~Hz}$ and amplitude $10.2 \mathrm{~mm} / \mathrm{sec}$. are designated by a cursor.

The maximal vibration level of the machine becomes localized on electric motor bearings. The data of root-mean-square value of vibration velocity are shown in Table 1 below.

Table 1. Data of vibration velocity of root-mean-square value.

\begin{tabular}{|c|c|c|}
\hline point & $\begin{array}{c}\text { Vertical direction } \\
\mathrm{mm} / \mathrm{sec}\end{array}$ & $\begin{array}{c}\text { Crosswise direction } \\
\mathrm{mm} / \mathrm{sec}\end{array}$ \\
\hline $\begin{array}{c}\text { Bearing 1 (electric motor) - rolling } \\
\text { bearing }\end{array}$ & 15.1 & 12.6 \\
\hline $\begin{array}{c}\text { Bearing 2 (electric motor) - rolling } \\
\text { bearing }\end{array}$ & 4.7 & 11.08 \\
\hline Bearing 3 (pump) - sliding bearing & 10.3 & 14.9 \\
\hline Bearing 4 (pump) - sliding bearing & 7.1 & 5.3 \\
\hline
\end{tabular}

According to the nameplate of the pump of the brand CPS 180-900 permissible (acceptable) level of the vibration velocity is $7.1 \mathrm{~mm} / \mathrm{sec}$.

\section{Results}

According to the diagnostic features (indicators) the major cause is likely high vibration:

- rotor out-of-balance of the electric motor (including half-coupling and blower of a stator frame);

- increased sliding bearing clearance;

- $\quad$ increased retaining clearance in the bearing bracket №3 of a pump.

- The analysis of results:

- Due to large balancing mass required the attempt to balance the rotor in its bearings onsite without disassembling is impossible;

- Rolling bearings №3 and №4 of a pump are without any evident defects, rotor and pump impellers out-of-balance condition is not diagnosed;

- the increase of vibration level of bearing housing №3 of the pump is likely associated with high vibration of the rotor of electric motor and the presence of clearings in the node.

- Measures and recommendations:

- It is necessary to balance the electric motor rotor in a set with a clutch on a balancer; 
- To inspect the rotor located on the open storage in order to reduce the repair and maintenance time. It is necessary to test the quality of sliding bearings to be sure that they are of high quality;

- After rotor inspection and complete assembly of the induction motor with a pump it is reasonable to carry out its idle run.

\section{Conclusion}

To sum up, we came to the following conclusions:

- vibration-based diagnostics on the mean-square value of vibration velocity using the vibration analyzer "Quartz" and software "Diamond- 2" allows conducting diagnostic study during the induction motor operation. It makes this technique one of the most perspective in the diamond industry.

- This technique allows recording mechanical defects in the induction motor which make up more than $40 \%$ of all faults.

- The findings enable to plan some required measures and recommendations for further maintenance and service which results in the reduction of the equipment idle time when there are some failures and also shows positive economic effect.

\section{References}

1. M. V. Vedyashkin, O. P. Muravlev, Russian Electrical Engineering, 84, 397 (2013)

2. O. P. Muravlev, V. P. Shevchuk, V. V. Gusev, Proceedings of institutions of higher education. Power engineering problems, 183 (2008)

3. V. V. Gusev, O. P. Muravlev, V. P. Shevchuk, Bulletin of Tomsk Polytechnic University, 314, 74 (2009)

4. S. I. Zakharov, Russian Engineering Research, 29, 602 (2009)

5. A. N. Novozhilov, E. V. Kryukova, T. A. Novozhilov, Russian Electrical Engineering, 85, 457 (2014)

6. K. A. Kuznetsov, Journal of Machinery Manufacture and Reliability, 45, 32 (2016)

7. M. P. Kozochkin, F. S. Sabirov, A. N. Bogan, K. V. Myslivtsev, Russian Engineering Research, 33, 486 (2013) 